\title{
The effect of adenomyosis on the outcomes of laparoscopic hysterectomy
}

\author{
Ali Yavuzcan, Alper Başbuğ, Merve Baştan, Mete Çağlar, İsmail Özdemir \\ Department of Obstetrics and Gynecology, Düzce University School of Medicine, Düzce, Turkey
}

\begin{abstract}
Objective: The presence of adenomyosis (ADS) may increase complication rates associated with laparoscopic hysterectomy (LH) due to an increased weight of the uterus, increased vascularization of the uterus, impaired myometrial tissue, and presence of additional gynecological pathologies such as leiomyoma or endometriosis. The aim of the present study was to evaluate perioperative and early postoperative parameters in patients with or without adenomyotic lesions.

Material and Methods: The study included patients who underwent LH in a university hospital. Patient data were retrieved from the hospital records and reviewed retrospectively. Sixty-one patients (85.9\%) without adenomyotic lesions comprised the control group. Ten patients with adenomyotic lesions (14.1\%) were regarded as the study group.

Results: In this study, the mean age of the patients was 50.93 \pm 9.39 years. The mean uterus size was significantly higher in patients with ADS $(p=0.02)$. There was no statistically significant difference in perioperative variables such as delta hemoglobin $(\mathrm{Hb})$, insertion of pelvic drainage catheter, and invasive assessment of the urinary tract between both the groups $(p=0.27, p=1.0$, and $p=0.67$, respectively). The difference between the groups in terms of postoperative blood transfusion was not statistically significant $(p=0.25)$. There was no statistically significant difference in the postoperative maximum body temperature, length of hospital stay, and duration of urinary catheterization between both the groups $(\mathrm{p}=0.77, \mathrm{p}=0.36$, and $\mathrm{p}=0.75$, respectively).
\end{abstract}

Conclusion: LH appears to be a safe alternative for patients with ADS. Large-scale, prospective, and randomized trials are required in order to suggest the routine use of LH in patients preoperatively diagnosed with ADS. (J Turk Ger Gynecol Assoc 2016; 17: 150-4)

Keywords: Adenomyosis, laparoscopic hysterectomy, outcomes

Received: 17 April, 2016 Accepted: 14 July, 2016

\section{Introduction}

Adenomyosis (ADS) is a benign gynecological condition where ectopic endometrial glands invade into the myometrium, resulting in hyperplasia of the adjacent smooth muscle (1). The prevalence of ADS in hysterectomy specimens was found to be $28.2 \%$ in a study (2). Studies have demonstrated the occurrence of invasive adenomyotic lesions associated with increased levels of matrix metalloproteinases (MMPs) and showed increased levels of vascular endothelial growth factor (VEGF) in patients with ADS $(3,4)$. The progressive enlargement of the uterus due to adenomyotic lesions is considered to cause symptoms such as abnormal uterine bleeding (AUB), dysmenorrhea, and uterine tenderness (5). ADS is often accompanied by endometriosis and leiomyomas (5). However, there is a debate over the definitive diagnosis of ADS in the preoperative period based on demographic features and patient symptoms (6).

There is currently no diagnostic imaging method or standard treatment approach for ADS (7). Although medical therapies involving antiestrogenic drugs, gonadotropin-releasing hormone agonists (GnRH-a), and levonorgestrel-releasing intra- uterine systems are used to control the symptoms of ADS as it is an estrogen-dependent condition, hysterectomy still remains the definitive treatment for this disease $(5,8)$. Abdominal, vaginal, or laparoscopic hysterectomy (LH) can be performed in patients that are considered to have ADS (5).

LH is a popular technique. Because it has better cosmetic results and short recovery time (9).Performing LH is popular among surgeons because it facilitates faster recovery, faster return to work, and better cosmetic outcomes (9). Wu et al. (10) declared that $\mathrm{LH}$ is performed in $12 \%$ of cases. LH has a rate of $10 \%$ among other hysterectomy methods. Overall, LH is not preferred due to higher rates of major surgical complications (11). On the other hand, complication rates in LH increase as the uterus size increases (12). Supracervical LH can be performed in patients with benign uterine conditions such as ADS. However, Sasaki et al. (13) argued that postoperative persistent vaginal bleeding may present due to residual adenomyotic foci in the endometrial tissue remaining in the cervical stump or adenomyotic lesions that may get implanted on the stump during morcellation after supracervical LH.

The presence of ADS may increase complication rates associated with LH due to the increased weight of uterus, in- 
creased vascularization of uterus, impaired myometrial tissue, and presence of additional gynecological pathologies such as leiomyoma or endometriosis. The aim of the present study was to evaluate perioperative and early postoperative parameters in patients with or without adenomyotic lesions.

\section{Material and Methods}

The study included patients who underwent LH in the Department of Obstetrics and Gynecology at Düzce University School of Medicine between August 1, 2012, and December 1, 2015. Patient data were retrieved from the university records and retrospectively reviewed. Out of the 94 patients who underwent LH, 71 were found to be eligible for our study. The study group comprised patients who were found to have adenomyotic lesions in the postoperative histopathologic examination of tissue sections, and the control group comprised patients who did not have any adenomyotic lesions.

All patients underwent bimanual pelvic examination, transvaginal ultrasonography (USG), cervico-vaginal smear, and endometrial tissue sampling in order to rule out the presence of any malignancy before surgery (9). The patients that had undergone cesarean section, hysterotomy, adnexal surgery, appendectomy, rectosigmoid surgery, or similar surgery in the pelvic area in the past were considered to have a positive history of pelvic surgery. The patients with uterovaginal prolapse, descensus uteri, and any defect in the anterior or posterior compartment of the vagina in the preoperative period were considered to have prolapse of the pelvic organs. The patients who were found to have focal/generalized and simple/complex endometrial hyperplasia with or without atypical changes in the preoperative examination of the endometrial tissue samples were classified under endometrial hyperplasia, which was used as an indication for surgery. The patients with a preoperative diagnosis of AUB who were found to have a demonstrable uterine pathology such as accompanying leiomyoma of the uterus, endometrial polyps, or endometrial hyperplasia were classified under the relevant uterine pathology as an indication for surgery. The patients with uterine bleeding but without a demonstrable cause were preoperatively classified as AUB.

Bowel preparation involved the administration of oral laxatives and rectal enema 1 day before the surgery. The anesthesiologist recorded the operation time based on the patient followup forms. Delta hemoglobin ( $\mathrm{Hb}$ ) was defined as the difference between preoperative and postoperative Hb levels (9). A pelvic drainage system was placed before the completion of surgery in some patients, if deemed necessary by the attending surgeon. The diagnosis of postoperative fever was confirmed only when the body temperature was $\geq 100.4^{\circ} \mathrm{F}\left(38^{\circ} \mathrm{C}\right)$ in 2 subsequent measurements within 4- to 6-hour intervals 24 hours after the surgery or if body temperature persisted at $\geq 101^{\circ} \mathrm{F}\left(38.3^{\circ} \mathrm{C}\right)$ in the postoperative period (14). In patients without fever, the highest body temperature measured in the postoperative period was recorded as the "maximum body temperature." Massive hemorrhage, need for reoperation due to other reasons, urinary tract injuries, and bowel and major vessel injuries were considered as major complications.
The patients were re-assessed every 24 hours in the postoperative period. The time to remove urinary catheters and the discharge time were recorded as the time interval during which they occurred, namely, 0-24, 24-48, or 48-72 hours. The patients without the need for opioids, exhibiting urinary retention, and mobile patients who were able to dress on their own were discharged from the hospital (15).

Dr. A.Y. was involved in all the surgeries considered in this study, and LH was performed with the technique used by this surgeon. The patients who underwent surgery using other techniques and patients who underwent supracervical LH or non-gynecologic additional procedures, patients whose medical records could not obtained, and patients who were found to have a malignancy in the histopathologic examination of frozen sections or during preoperative/postoperative histopathologic examination were excluded from our study. The operation time was missing for 1 patient. The excised specimens were examined, and the pathology reports were issued by the same pathology department.

All procedures were performed under general anesthesia: the patients were placed in the lithotomy position. Urinary catheterization and insertion of a nasogastric tube were performed in all the patients. A manipulator was placed in the uterine cavity. The surgeon remained on the left-hand side of the patient during surgery. After creating pneumoperitoneum and a $10-\mathrm{mm}$ trocar sleeve placement, a 10-mm telescope was passed through this sleeve. Two 5-mm trocar sleeves were placed in the right and left hypochondrium regions lateral to the rectus abdominis muscle and inferior epigastric vessels in the outer one-third of the distance between the anterior superior iliac spine and umbilicus. A 5- or 10-mm trocar sleeve was placed $3 \mathrm{~cm}$ below the left costal margin at the midclavicular line (Palmer's point). A vessel-sealing device (LigaSure ${ }^{\mathrm{TM}}$, Covidien; Boulder, Colorado, USA) or ultrasonic scalpel (Harmonic Ace ${ }^{\circledR}$, Ethicon Endo-Surgery Inc.; Cincinnati, OH, USA) was passed through the trocar placed at the Palmer's point. A 5-mm dissector and grasping forceps were passed through the trocars placed in the two lower quadrants. A manipulator was used to elevate the uterus from the pelvic floor during surgery, while paying particular attention to the possible projection of the ureter below the peritoneum. Hemostasis was achieved in the infundibulopelvic ligament in patients that underwent salpingo-oophorectomy and in the utero-ovarian ligament in patients that did not undergo salpingo-oophorectomy. The bladder was dissected from the lower segment of the uterus and superior portion of the vagina. The uterine arteries were skeletonized, coagulated, and separated on both sides using LigaSure. The vaginal wall was completely separated from the cervix using Harmonic Ace $₫$ above the sacrouterine ligaments and vaginal fornices delineated with a manipulator. The vaginal cuff was stitched with absorbable sutures having increased strength using the transvaginal or laparoscopic approach.

For a large uterus (weight $>280$ g or gestation size $>12$ weeks) during inspection before surgery, the operation proceeded with the method used by Yavuzcan et al. (9) in their previous study. Patients in whom the trajectory of the ureter could not be clearly observed or in patients with a high index of suspicion 
for injury to the urinary tract or patients that had a difficult bladder dissection underwent diagnostic cystoscopy and/or ureteral catheterization at the end of the procedure. These patients were recorded as "patients that underwent invasive assessment of the integrity of the urinary tract." Surgical procedures to treat stress urinary incontinence, corrective surgery for the prolapse of pelvic organs, and perineoplasty procedures were regarded as additional genitourinary surgical procedures.

In the present study, the histopathological examination of multiple sections obtained from the hysterectomy specimens revealed the presence of ADS in 10 patients (14.1\%), which comprised the study group. The remaining 61 patients $(85.9 \%)$ without ADS comprised the control group.

Descriptive statistics included mean, standard deviation, and ratio. Data from the t-test performed on the independent samples was used in the analysis of the qualitative data, and Fisher's exact test was used to compare the quantitative data between both the groups. SPSS version 19.0 (IBM SPSS Statistics for Windows, Version 19.0, IBM Corporation; New York, USA) software package was used in the statistical analysis. In our case, $\mathrm{p}<0.05$ was considered to be statistically significant.

\section{Results}

In this study, the mean age of the patients was $50.93 \pm 9.39$ years. The indication for surgery was uterine fibroids in 23 patients (32.4\%) and AUB in 14 patients (19.7\%), and prediagnosis of ADS in the preoperative period happened in only 1 patient $(1.4 \%)$. Out of the patients that underwent LH, 14 patients (19.7\%) also underwent additional surgery to their genitourinary system. The characteristics of the patients are presented in Table 1.

Out of the patients who exhibited adenomyotic lesions, 6 patients (60\%) had concurrent leiomyoma, 4 patients (40\%) had chronic cervicitis, and 2 patients (20\%) had salpingitis isthmica nodosa (SIN). Out of the 61 patients (85.9\%) without adenomyotic lesions in the control group, 41 patients (67.2\%) had concurrent chronic cervicitis, 29 patients (47.5\%) had leiomyoma, and 5 patients $(8.1 \%)$ had 1 of the subtypes of endometrial hyperplasia.

The mean uterus size was significantly higher in patients with adenomyotic lesions (290.30 \pm 179.41 vs. $173.52 \pm 138.49 \mathrm{~g}$, $\mathrm{p}=0.02$ ). There was no statistically significant difference in the perioperative variables such as delta $\mathrm{Hb}$, insertion of pelvic drainage catheter, and invasive assessment of the urinary tract between both the groups $(\mathrm{p}=0.27, \mathrm{p}=1.0$, and $\mathrm{p}=0.67$, respectively) (Table 2).

Blood transfusion was required in the postoperative period in 2 patients (20\%) with adenomyotic lesions in the study group and 5 patients $(8.1 \%)$ without adenomyotic lesions in the control group; however, the difference between the groups was not statistically significant $(p=0.25)$. There was no statistically significant difference in the postoperative maximum body temperature, length of hospital stay, and duration of urinary catheterization between both the groups $(p=0.77, p=0.36$, and $p=0.75$, respectively) (Table 3 ).
Table 1. General patients' characteristics

\begin{tabular}{|c|c|c|c|}
\hline & $\begin{array}{c}n=71 / \\
(100 \%)\end{array}$ & Mean \pm SD & $\begin{array}{l}\text { Min. - } \\
\text { Max. }\end{array}$ \\
\hline Age & $71(100 \%)$ & $50.93 \pm 9.39$ & $38-79$ \\
\hline Parity & $71(100 \%)$ & $3.38 \pm 2.00$ & $0-9$ \\
\hline Gravida & $71(100 \%)$ & $3.87 \pm 2.70$ & $0-17$ \\
\hline Past history of pelvic surgery (+) & $20(28.2 \%)$ & & \\
\hline Use of morcellation & $5(7 \%)$ & & \\
\hline Additional genitourinary surgery & $14(19.7 \%)$ & & \\
\hline Mean operation time, $\mathrm{t}(\min ) \gamma$ & $70(98.5 \%)$ & $158.39 \pm 45.54$ & $75-300$ \\
\hline Major complication & $3(4.2 \%)$ & & \\
\hline \multicolumn{4}{|l|}{ Indications } \\
\hline - Leiomyoma & $23(32.4 \%)$ & & \\
\hline - $\mathrm{AUB}$ & $14(19.7 \%)$ & & \\
\hline - Adnexial mass & $7(9.9 \%)$ & & \\
\hline - Prolapse of the pelvic organs & $6(8.5 \%)$ & & \\
\hline - Endometrial hyperplasia & $5(7.0 \%)$ & & \\
\hline - Pelvic mass & $4(5.6 \%)$ & & \\
\hline - Cervical premalignant lesion & $3(4.2 \%)$ & & \\
\hline - ADS+chronic pelvic pain & $1(1.4 \%)$ & & \\
\hline - Other & $8(11.2 \%)$ & & \\
\hline \multicolumn{4}{|l|}{$\gamma$ missing data in 1 patient } \\
\hline
\end{tabular}

Table 2. Comparison of perioperative variables

\begin{tabular}{|c|c|c|c|}
\hline & $\begin{array}{c}\text { ADS (-) } \\
n=61(85.9 \%)\end{array}$ & $\begin{array}{c}\text { ADS }(+) \\
n=10(14.1 \%)\end{array}$ & $\mathbf{p}$ \\
\hline Weight of uterus (gr.) ${ }^{\alpha}$ & $173.52 \pm 138.49$ & $290.30 \pm 179.41$ & 0.02 \\
\hline Delta $\mathrm{Hb}(\mathrm{gr} / \mathrm{dL})^{\alpha}$ & $1.64 \pm 1.11$ & $2.14 \pm 2.36$ & 0.27 \\
\hline Pelvic drainage catheter ${ }^{\mathrm{a}}$ & $18(29.5 \%)$ & $3(33.3 \%)$ & 1.0 \\
\hline Inv. assess. of urinary tract. ${ }^{a}$ & $12(19.6 \%)$ & $1(10 \%)$ & 0.67 \\
\hline \multicolumn{4}{|c|}{$\begin{array}{l}{ }^{a} \text { Mean } \pm \text { Standard Deviation } \\
{ }^{a} \mathrm{nv}(\%) \\
* \mathrm{p}<0.05 \text { was considered statistically significant. } \\
\text { Inv. assess. of urinary tract.: patients that underwent invasive assessment } \\
\text { of the integrity of the urinary tract; ADS: adenomyosis; Hb: hemoglobin }\end{array}$} \\
\hline
\end{tabular}

Table 3. Comparison of postoperative variables

\begin{tabular}{|c|c|c|c|}
\hline & $\begin{array}{c}\text { ADS (-) } \\
(n=61)\end{array}$ & $\begin{array}{c}\operatorname{ADS}(+) \\
(n=10)\end{array}$ & $\mathbf{p}$ \\
\hline Length of Hospital Stay (days) ${ }^{\alpha}$ & $3.38 \pm 1.62$ & $2.90 \pm 0.73$ & 0.36 \\
\hline Urinary Catheterization (days) $^{\alpha}$ & $1.23 \pm 0.66$ & $1.30 \pm 0.48$ & 0.75 \\
\hline Postoper. max. body temp. $\left({ }^{\circ} \mathrm{C}\right)^{\alpha}$ & $36.78 \pm 0.50$ & $36.82 \pm 0.27$ & 0.77 \\
\hline Blood Tx. Requirement $^{\mathrm{a}}$ & $5(8.1 \%)$ & $2(20 \%)$ & 0.25 \\
\hline \multicolumn{4}{|c|}{$\begin{array}{l}{ }^{a} \text { Mean } \pm \text { Standard Deviation } \\
{ }^{a} \mathrm{n}(\%) \\
\text { *p }<0.05 \text { was considered statistically significant. } \\
\text { Postoper. max. body temp.: postoperative maximum body temperature } \\
\text { ADS: adenomyosis }\end{array}$} \\
\hline
\end{tabular}




\section{Discussion}

The definitive diagnosis of ADS is based on the examination of hysterectomy materials in the postoperative period (16). There are ongoing studies attempting to accurately diagnose ADS using noninvasive and minimally invasive methods (16). USG and magnetic resonance imaging (MRI) can be helpful in the preoperative period (16). Also, Exacoustos et al. (17) reported that the coronal section of the uterus obtained by three-dimensional transvaginal ultrasound (3D-TVS) permits the accurate evaluation and measurement of the JZ, and its alteration has good diagnostic accuracy for ADS. In the present study, only 1 patient (1.4\%) was diagnosed with ADS in the preoperative period. A hysteroscopic biopsy can diagnose ADS (18). Traditionally, laparoscopy has no place in the diagnosis of ADS (16). On the other hand, minimally invasive procedures may be used to treat ADS. In a recent study it was estimated that laparoscopic or robotic adenomyomectomy was feasible and safe for women with severely symptomatic ADS who requested uterine preservation (19). ADS does not usually cause marked pathological changes in the serosa of the uterus. On the other hand, Graziano et al. (16) reported that an irregular structure of the uterus, blue discoloration after performing the methylene blue dye test, and decreased resistance of the uterus during manipulation could be characteristic features of ADS.

Laparoscopic findings of ADS are probably associated with underlying endometrial pathological lesions and altered uterine vascularization. ADS islets invading deep into the endometrial line are scattered within the muscle structure of the uterus (20). Although various definitions have been made regarding the distance of invasion below the endometrial line, definitive criteria are still debated (16). The posterior wall of the uterus is commonly involved in ADS, which exhibits irregular enlargement (1). In the present study, the mean weight of the uterus was significantly higher in patients with adenomyotic lesions $(290.30 \pm 179.41 \mathrm{~g}$ vs. $173.52 \pm 138.49 \mathrm{~g}, \mathrm{p}=0.02)$. Uterine fibroids are common findings accompanying ADS. The occurrence of uterine fibroids is another condition that causes the enlargement of the uterus. Vercellini et al. (20) reported that ADS is accompanied by uterine fibroids and menorrhagia in $23 \%$ patients. Similarly, in the present study, $60 \%$ patients with adenomyotic lesions had concurrent uterine leiomyoma. It is also known that an increasing weight of the uterus decreases visibility and unfavorably influences the performance of endoscopic devices (21). Increased weight of the uterus is also associated with increased perioperative blood loss during LH (22). The structure of vessels supplying a large uterus becomes thicker (22). Goteri et al. (4) claimed that there has been a marked increase in the development of microvessels in patients with ADS. The lesions of ADS have been shown to be hypervascularized tissues due to high VEGF content (23). Considering all these factors, increased perioperative blood loss and increased need for postoperative blood transfusion can be expected during $\mathrm{LH}$ in patients with ADS. However, there was no statistically significant difference in delta $\mathrm{Hb}(\mathrm{p}=0.27)$ and need for blood transfusion $(\mathrm{p}=0.25)$ between patients with or without adenomyotic lesions in our study.
Urinary tract injury occurred in 1.3\% of LH operations, with ureteral injuries almost as common as bladder injuries (24). American College of Obstetrics and Gynecology (ACOG) recommended the use of cystoscopy in patients with a high index of suspicion for urinary tract injuries (25). The highest risk of ureter trauma occurs in the neighborhood of the uterine artery (24). Manoucheri et al. (26) claimed that performing cranial deviation of the uterus with upward pressure on the uterine manipulator before cauterizing or incising uterine vessels or using upward traction on the uterine specimen with a laparoscopic tenaculum in lieu of a uterine manipulator are important for avoiding ureter injuries. Traction and countertraction are two important steps for maintaining hemostasis at the uterine artery level while performing LH (27). The difficulty of manipulating the uterus reported among the findings of ADS in the study by Graziano et al. (16) is possibly associated with the increased level of MMPs and increased angiogenesis (3). MMPs are proteolytic enzymes, which have the potential capacity of degrading the extracellular matrix (ECM) components (28). In particular, MMP-2 and MMP-9 disintegrate typeIV collagen, which is the main component of the basement membrane (29). A study has demonstrated a marked increase in MMP-2 and MMP-9 levels in the ADS tissue (3). An invasive assessment of the urinary tract, placement of pelvic drainage system to monitor postoperative hemorrhage, and performing prolonged urinary catheterization due to urinary tract injury can be expected in patients with ADS having difficulty in uterine manipulation and additional gynecologic pathologies such as leiomyoma and endometriosis; however, the present study found no difference in these parameters between patients with or without adenomyotic lesions $(p=0.67, p=1.0$, and $\mathrm{p}=0.75$, respectively).

Further, VanEvert et al. (30) reported that LH is associated with a reduction in postoperative wound infections. Brummer et al. (31) reported that a febrile event is less common with a more experienced LH surgeon. The experience of the surgeon who has performed fewer than 30 LHs was an independent risk factor for febrile events. All of the operations were performed under the management of the same experienced surgeon in the present study, so that none of the patients had postoperative fever and there was no difference between both the groups in terms of postoperative maximum body temperature $(p=0.77)$. In addition, the length of hospital stay did not differ significantly between patients with or without adenomyotic lesions $(\mathrm{p}=0.36)$.

According to the results of the present study, LH appears to be a safe alternative in patients with ADS. Large-scale, prospective, and randomized trials are required in order to suggest the routine use of LH in patients preoperatively diagnosed with ADS.

Ethics Committee Approval: Ethics committee approval was received for this study from the ethics committee of Düzce University School of Medicine (2016/32).

InformedConsent: $N / A$.

Peer-review: Externally peer-reviewed.

Author Contributions: Concept - A.Y.; Design - A.Y., M.Ç., I.Ö.; Supervision - A.Y.; Resources - A.B., M.B.; Materials - A.B., M.B.; Data Collec- 
tion and/orProcessing - A.B., M.B.; Analysis and/or Interpretation - A.Y.; Literature Search - A.Y.; Writing Manuscript - A.Y.; Critical Review - A.Y., M.Ç., I.Ö.

Conflict of Interest: No conflict of interest was declared by the authors.

Financial Disclosure: The authors declared that this study has received no financial support.

\section{References}

1. Ferenczy A. Pathophysiology of Adenomyosis. Hum Reprod Update 1998; 4: 312-22. [Crossref]

2. Parazzini F, Mais V, Cipriani S, Busacca M, Venturini P; GISE. Determinants of Adenomyosis in women who underwent hysterectomy for benign gynecological conditions: results from a prospective multicentric study in Italy. Eur J Obstet Gynecol Reprod Biol 2009; 143: 103-6. [Crossref]

3. Li T, Li YG, Pu DM. Matrix metalloproteinase-2 and -9 expression correlated with angiogenesis in human Adenomyosis. Gynecol Obstet Invest 2006; 62: 229-35. [Crossref]

4. Goteri G, Lucarini G, Montik N, Zizzi A, Stramazzotti D, Fabris G, et al. Expression of vascular endothelial growth factor (VEGF), hypoxia inducible factor-1 alpha (HIF-1 alpha), and microvessel density in endometrial tissue in women with adenomyosis. Int $\mathrm{J}$ Gynecol Pathol 2009; 28: 157-63. [Crossref]

5. Pepas L, Deguara C, Davis C. Update on the surgical management of Adenomyosis. Curr Opin Obstet Gynecol 2012; 24: 259-64. [Crossref]

6. Vercellini P, Viganò P, Somigliana E, Daguati R, Abbiati A, Fedele L. Adenomyosis: epidemiological factors. Best Pract Res Clin Obstet Gynaecol 2006; 20: 465-77. [Crossref]

7. Struble J, Reid S, Bedaiwy MA. Adenomyosis; A Clinical Review of a Challenging Gynecologic Condition. J Minim Invasive Gynecol 2016; 23: 164-85. [Crossref]

8. Scarperi S, Pontrelli G, Campana C, Steinkasserer M, Ercoli A, Minelli L, et al. Laparoscopic Radiofrequency Thermal Ablation for Uterine Adenomyosis. JSLS 2015; 19: pii: e2015.00071

9. Yavuzcan A, Cağlar M, Ustün Y, Dilbaz S, Kumru S. Evaluation of the outcomes of laparoscopic hysterectomy for normal and enlarged uterus (>280 g). Arch Gynecol Obstet 2014; 289: 831-7. [Crossref]

10. Wu JM, Wechter ME, Geller EJ, Nguyen TV, Visco AG. Hysterectomy rates in the United States, 2003. Obstet Gynecol 2007; 110: 1091-5. [Crossref]

11. Kluivers KB, Johnson NP, Chien P, Vierhout ME, Bongers M, Mol BW. Comparison of laparoscopic and abdominal hysterectomy in terms of quality of life: a systematic review. Eur J Obstet Gynecol Reprod Biol 2008; 136: 3-8. [Crossref]

12. Bonilla DJ, Mains L, Whitaker R, Crawford B, Finan M, Magnus M. Uterine weight as a predictor of morbidity after a benign abdominal and total laparoscopic hysterectomy. J Reprod Med 2007; 52: 490-8.

13. Sasaki KJ, Cholkeri-Singh A, Sulo S, Miller CE. Persistent bleeding after laparoscopic supracervical hysterectomy. JSLS 2014;18: pii: e2014.002064.

14. Lachiewicz MP, Moulton LJ, Jaiyeoba O. Infection Prevention and Evaluation of Fever After Laparoscopic Hysterectomy. JSLS 2015;19: pii: e2015.00065.

15. Jørgensen H, Fomsgaard JS, Dirks J, Wetterslev J, Andreasson B, Dahl JB. Effect of peri- and postoperative epidural anaesthesia on pain and gastrointestinal function after abdominal hysterectomy. $\mathrm{Br}$
J Anaesth 2001; 87: 577-83. [Crossref]

16. Graziano A, Lo Monte G, Piva I, Caserta D, Karner M, Engl B, et al. Diagnostic findings in adenomyosis: a pictorial review on the major concerns. Eur Rev Med Pharmacol Sci 2015; 19: 1146-54.

17. Exacoustos C, Brienza L, Di Giovanni A, Szabolcs B, Romanini ME, Zupi E, Arduini D. Adenomyosis: three-dimensional sonographic findings of the junctional zone and correlation with histology. Ultrasound Obstet Gynecol 2011; 37: 471-9. [Crossref]

18. Dakhly DM, Abdel Moety GA, Saber W, Gad Allah SH, Hashem AT, Abdel Salam LO. Accuracy of Hysteroscopic Endomyometrial Biopsy in Diagnosis of Adenomyosis. J Minim Invasive Gynecol 2015: pii: S1553-4650(15)01663-5.

19. Chong GO, Lee YH, Hong DG, Cho YL, Lee YS. Long-Term Efficacy of Laparoscopic or Robotic Adenomyomectomy with or without Medical Treatment for Severely Symptomatic Adenomyosis. Gynecol Obstet Invest 2016; 81: 346-52. [Crossref]

20. Vercellini P, Parazzini F, Oldani S, Panazza S, Bramante T, Crosignani PG. Adenomyosis at hysterectomy: a study on frequency distribution and patient characteristics. Hum Reprod 1995; 10: 1160-2.

21. Zeng W, Chen L, Du W, Hu J, Fang X, Zhao X. Laparoscopic hysterectomy of large uteri using three-trocar technique. Int J Clin Exp Med 2015; 86319-26.

22. Dassel MW, O'Hanlan KA, Shwayder JM. Ultrasonographically calculated uterine mass as a predictor for surgical outcomes in total laparoscopic hysterectomy. J Gynecol Surg 2015; 31: 128-34. [Crossref]

23. Ota H, Igarashi S, Tanaka T. Morphometric evaluation of stromal vascularization in the endometrium in adenomyosis. Hum Reprod 1998; 13: 715-9. [Crossref]

24. Tan-Kim J, Menefee SA, Reinsch CS, O'Day CH, Bebchuk J, Kennedy JS, Whitcomb EL. Laparoscopic Hysterectomy and Urinary Tract Injury: Experience in a Health Maintenance Organization. J Minim Invasive Gynecol 2015; 22: 1278-86. [Crossref]

25. AAGL Practice Report: Practice guidelines for intraoperative cystoscopy in laparoscopic hysterectomy. AAGL Advancing Minimally Invasive Gynecology Worldwide. J Minim Invasive Gynecol 2012; 19: 407-11. [Crossref]

26. Manoucheri E, Cohen SL, Sandberg EM, Kibel AS, Einarsson J. Ureteral injury in laparoscopic gynecologic surgery. Rev Obstet Gynecol 2012; 5: 106-11.

27. Jelovsek JE, Chiung C, Chen G, Roberts SL, Paraiso MF, Falcone T. Incidence of lower urinary tract injury at the time of total laparoscopic hysterectomy. JSLS 2007; 11: 422-7.

28. Egeblad M, Werb Z. New functions for the matrix metalloproteinases in cancer progression. Nat Rev Cancer 2002; 2: 161-74. [Crossref]

29. Laios A, Mohamed BM, Kelly L, Flavin R, Finn S, McEvoy L, et al. Pre-Treatment of platinum resistant ovarian cancer cells with an MMP-9/MMP-2 inhibitor prior to cisplatin enhances cytotoxicity as determined by high content screening. Int J Mol Sci 2013; 14: 2085103. [Crossref]

30. VanEvert JS, Smeenk JM, Dijkhuizen FP, de Kruif JH, Kluivers KB. Laparoscopic subtotal hysterectomy versus laparoscopic total hysterectomy: a decade of experience. Gynecol Surg 2010; 7: 9-12. [Crossref]

31. Brummer TH, Jalkanen J, Fraser J, Heikkinen AM, Kauko M, Mäkinen J, et al. FINHYST, a prospective study of 5279 hysterectomies: complications and their risk factors. Hum Reprod 2011; 26: 1741-51. [Crossref] 